\title{
Cryoballoon ablation for treatment of patients with refractory esophageal neoplasia after first line endoscopic eradication therapy
}

\section{다 (우우}

\author{
Authors \\ Haidry ${ }^{1,2}$ \\ Institutions \\ 1 Division of Surgery and interventional science, \\ University College London (UCL), London, UK \\ 2 Department of Gastroenterology, University College \\ London Hospital (UCLH), London, UK \\ 3 Department of Histopathology, University College \\ London Hospital (UCLH), London, UK
}

Durayd Alzoubaidi ${ }^{1}$, Mohamed Hussein'1, Vinay Sehgal², Christwishes Makahamadze², Cormac G. Magee ${ }^{2}$, Martin Everson ${ }^{2}$, David Graham ${ }^{2}$, Rami Sweis ${ }^{2}$, Matthew Banks ${ }^{2}$, Sarmed S. Sami ${ }^{1}$, Marco Novelli ${ }^{3}$, Laurence Lovat ${ }^{1}$, Rehan

submitted 4.12 .2019

accepted after revision 12.2 .2020

\author{
Bibliography \\ DOI https://doi.org/10.1055/a-1149-1414 | \\ Endoscopy International Open 2020; 08: E891-E899 \\ (c) Georg Thieme Verlag KG Stuttgart · New York \\ eISSN 2196-9736
}

Corresponding author

Durayd Alzoubaidi, Charles Bell House,

43-45 Foley Street, London, W1W 7TS

Fax: + 07828074691

d.alzoubaidi@ucl.ac.uk

\section{ABSTRACT}

Background and study aims Cryoablation with the Cryoballoon device is a novel ablative therapy that uses cycles of freezing and thawing to induce cell death. This single-cen- ter prospective study evaluated the feasibility of the focal cryoablation device for the treatment of areas of refractory esophageal neoplasia in patients who had undergone first line endoscopic eradication therapy (EET). Complete remission of dysplasia (CR-D) and complete remission of intestinal metaplasia (CR-IM) at first follow-up endoscopy, durability of disease reversal, rates of stenosis and adverse events were studied.

Patients and methods Eighteen cases were treated. At baseline, nine patients had low-grade dysplasia (LGD), six had high-grade dysplasia (HGD) and three had intramucosal carcinoma (IMC). Median length of dysplastic Barrett's esophagus (BE) treated was $3 \mathrm{~cm}$. The median number of ablations per patient was 11. Each selected area of visible dysplasia received 10 seconds of ablation. One session of cryoablation was performed per patient. Biopsies were performed at around 3 months post-ablation.

Results CR-D was achieved in $78 \%$ and CR-IM in $39 \%$ of patients. There were no device malfunction or adverse events. Stenosis was noted in $11 \%$ of cases. At a median follow up of 19 -months, CR-D was maintained in $72 \%$ of patients and CR-IM in $33 \%$.

Conclusions Cryoablation appears to be a viable rescue strategy in patients with refractory neoplasia. It is well tolerated and successful in obtaining CR-D and CR-IM in patients with treatment-refractory BE. Further trials of dosimetry, efficacy and safety in treatment-naïve patients are underway.

\section{Introduction}

Barrett's esophagus (BE) is a premalignant condition with metaplastic cells that can progress to esophageal adenocarcinoma. It is characterized by a change of normal squamous epithelial cells lining the esophagus to metaplastic columnar cells [1]. In most patients, BE only exists in the metaplastic stage without progression to dysplasia. Chronic exposure to acid reflux can result in epithelial cell inflammation and proliferation that can lead to the development of BE metaplasia and progression to low-grade dysplasia (LGD), high-grade dysplasia (HGD) and invasive esophageal adenocarcinoma [2]. Incidence of esophageal adenocarcinoma has increased in recent years and despite advances in medical and surgical interventions, long-term survival remains poor $[3,4]$ with less than $20 \%$ of patients surviving at 5 years [5]. Surgical management of early esophageal neoplasia carries significant mortality rates [6-8]. In recent years there have been significant developments in minimally in- 
vasive endoscopic eradication therapy (EET) of BE neoplasia with high eradication rates and a good safety profile.

Currently, endoscopic treatment of BE neoplasia consists of endoscopic resection (ER) of visible lesions for accurate staging and risk stratification of patients [9] followed by field ablation of remaining areas of flat BE to prevent the development of metachronous lesions [10]. The most commonly used and studied ablative modality is radiofrequency ablation (RFA), that utilizes pulsed radiofrequency energy to destroy superficial mucosal tissue with preservation of deeper tissue [11]. This technique has been shown to be effective in achieving CR-D and CR-IM; however it can result into pain, bleeding and stricture in the esophagus [12-14]. In a minority of patients, ablative therapy with RFA is ineffective and therefore alternative ablative techniques are warranted.

Recurrence of IM and dysplasia can occur after achieving CRIM and therefore surveillance has been recommended. Data from the United States RFA registry noted a $20 \%$ recurrence of BE over a follow-up period of 2.4 years and recurrence of dysplasia reported in $14 \%$ of those who had BE recurrence [5]. A systematic review and meta-analysis by Krishnamoorthi et al, showed a recurrence rate for IM to be $7.1 \%$ per patient year, $1.3 \%$ for LGD and $0.8 \%$ for HGD/EAC (after first line EET) [16].

$\mathrm{BE}$ refractory to endoscopic therapy has been documented in various studies with overall rate ranging from $2 \%$ to $25 \%$ $[12,17]$.

Treatment of BE neoplasia by endoscopic submucosal dissection (ESD) and endoscopic mucosal resection (EMR) have shown to be effective and less invasive than surgical esophagectomy. Both techniques allow histological assessment of resected specimens that can be used to guide further therapy; however, these techniques require advanced training in endoscopic therapy with noticeable adverse events (AEs) such as bleeding (2.1\%), perforation (2.5\%-5\%), and stenosis (10\%).

A new treatment for esophageal neoplasia has been developed. Cryoablation with the Cryoballoon device (cryoballoon focal ablation system, Pentax Medical Inc) is a novel ablative therapy that uses cycles of freezing (with nitrous oxide at-80 ${ }^{0} \mathrm{C}$ ) and thawing to induce cell death by intracellular and extracellular ice formation, leading to vascular injury, and ultimately apoptosis and cell death [18]. The technique may ablate deeper than RFA whilst preserving the extracellular matrix [19] and therefore may result into lower stricture rates and deeper tissue destruction [20]. In addition, recent studies have shown that cryoablation to be better tolerated by patients and to be less painful [21-23].

The aim of this study was to prospectively evaluate the feasibility of the focal cryoablation device for the treatment of areas of refractory esophageal neoplasia in patients who had undergone first line EET in a single high-volume tertiary referral center.

\section{Patients and methods}

Patients were treated by a single experienced endoscopist with several years' experience in advanced endoscopic management of esophageal neoplasia including resection and ablative modalities.

Refractory esophageal neoplasia was defined as failure of three ablative procedures (argon plasma coagulation [APC] or RFA) in patients with BE neoplasia or failure of two ablative procedures (APC or RFA) with less than $50 \%$ reduction of BE after the second ablation. Reduction in BE length was determined by measuring the remaining length of BE using the Prague classification.

The primary objectives were complete resolution of dysplasia (CR-D) and complete resolution of intestinal metaplasia (CRIM) at 3-month follow-up endoscopy. Secondary objectives included the rate of stenosis, AEs and durability of disease reversal. Stenosis was defined as any stricture causing symptomatic dysphagia to solid and liquid and strictures preventing the passage of an adult gastroscope requiring endoscopic dilatation.

Inclusion criteria are 18 or older; previous receipt of first-line EET (ER and ablation with RFA or APC for at least three sessions excluding cryoablation) in patients with BE neoplasia with biopsy proven residual disease; persistence of flat areas of esophageal neoplasia after first-line EET confirmed by two expert pathologists; and in patients with IMC, no evidence of poorly differentiated malignancy, involvement of deep resection margin (i. e. T1b deep), or lymphovascular involvement on previous ER specimens.

Exclusion criteria were presence of esophageal stricture preventing the passage of a therapeutic gastroscope and deployment of the Cryoballoon ablation device; active gastrointestinal bleeding or perforations; active inflammation in the upper gastrointestinal tract; and presence of raised or high-risk lesion requiring endoscopic resection.

The requirement for baseline was persistent BE with LGD, HGD, or IMC.

\section{Cryoablation device and endoscopic procedure}

The cryoablation balloon system has two main components: The delivery catheter with a balloon probe (30 $\mathrm{mm}$ in length) and a handheld controller device for application of the cryogenic fluid with a small cylinder containing the nitrous oxide. The delivery catheter utilizes one balloon probe for all sizes of esophagi ( $\mathbf{F i g}$. 1). The delivery catheter is introduced via the working channel of a therapeutic gastroscope (Pentax EG34i10) and the balloon is inflated by the trigger on the foot pedal. The balloon is automatically inflated until it reaches the diameter of the treated esophagus, hence preventing over inflation and trauma to the wall of the esophagus. The inflated balloon is cooled by spraying nitrous oxide via the diffuser within the inflated balloon, which subsequently freezes the targeted mucosa to $-80{ }^{\circ} \mathrm{C}$. The cryogenic spray covers an area of about $2 \mathrm{~cm}^{2}$. Rotation of the diffuser within the balloon (360 degree), is controlled by the foot pedal, which allows targeting of specific areas of the mucosa ( $\triangleright$ Fig. 2) [24]. Following deflation of the balloon, the gas is aspirated back automatically into the hand 

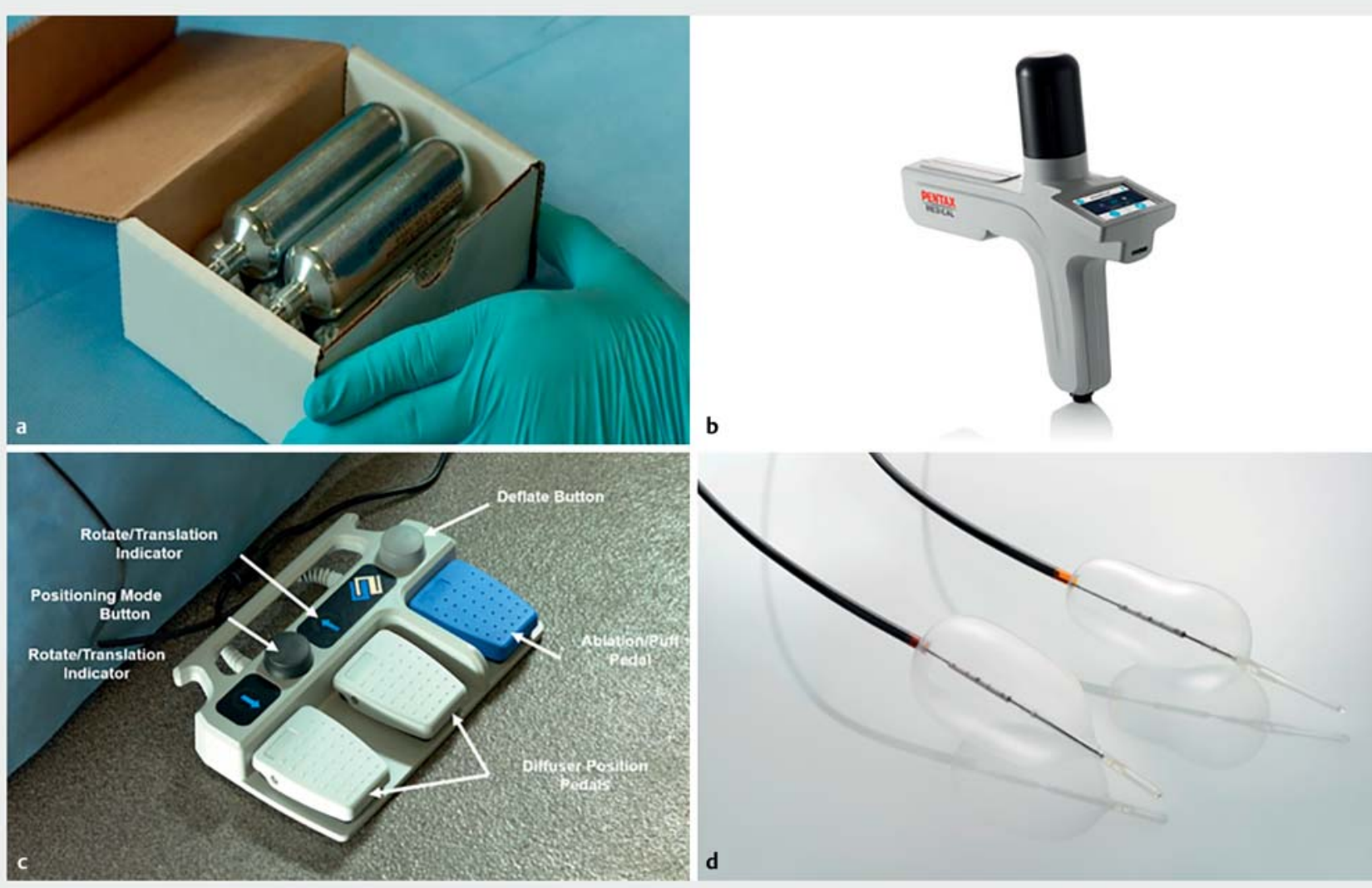

- Fig. 1 a Cylinders containing nitrous oxide as the cryogenic agent. b Hand-held controller device; $\mathbf{c}$ foot pedal; $\mathbf{d}$ cryoablation balloon catheters for the oesophagus and the GOJ junction. (Source $\mathbf{b}$ and $\mathbf{d}$ : PENTAX Medical)

held controller and condensed. The treated mucosa becomes erythematous immediately after deflation of the balloon, allowing the endoscopist clear visualisation of the treated segment of the mucosa.

\section{Endoscopic therapy and follow up}

The endoscopic procedure was performed under conscious sedation by the same gastrointestinal endoscopist. Refractory areas of BE were measured as per the Prague C \& M classification and careful inspection for any visible raised lesions was first carried out. The refractory areas of BE were ablated for 10 seconds by the cryoballoon device. After each ablation, the adjacent area was subsequently ablated until all areas of visible $\mathrm{BE}$ including the gastroesophageal junction (GOJ) were treated. In patients with long-segment $B E$, there was a minimum overlapping area of cryoablation to ensure that all areas were treated adequately. Scraping of the ablated mucosa was not performed.

All patients received post-ablative care, which included high-dose acid suppressive medication (omeprazole $40 \mathrm{mg}$ twice a day, ranitidine $300 \mathrm{mg}$ in the evening and sucralfate liquid $2 \mathrm{~g}$ three times a day) and a liquid diet for 24 hours followed by a soft diet for 1 week. All patients received follow-up endoscopy at about 3 months post-cryoablation. At follow-up endoscopy, all treated area were inspected with white light endoscopy (WLE), virtual chromoendoscopy (Narrow Band Imaging [NBI]) or optical enhancement (OE) and chromoendoscopy (with acetic acid). All remaining areas of neoplasia were documented. In addition, presence of stenosis, if any was also documented. Biopsies were then taken from $1 \mathrm{~cm}$ below the $G O J$, the $\mathrm{GO}$ and the remaining segment of $\mathrm{BE}$ at 2 -cm intervals, including target biopsies from any suspicious areas ( $\bullet$ Fig. $\mathbf{1}$ ).

\section{Biopsy specimen}

All biopsy specimens were placed in formalin and fixed in paraffin and subsequently stained with haematoxylin and eosin. All our histological specimens were examined by the same two senior BE expert pathologist (MN, MJ) at University College London Hospital (UCLH).

\section{Study approval and patient consent}

This project was presented to the local Clinical Effectiveness Steering Group (CESG) at UCLH for approval as a new procedure. The CESG committee gave their final approval in June 2016 and subsequently patient recruitment started. Written informed consent was taken from all participating patients prior to the endoscopic therapy with cryoablation. 


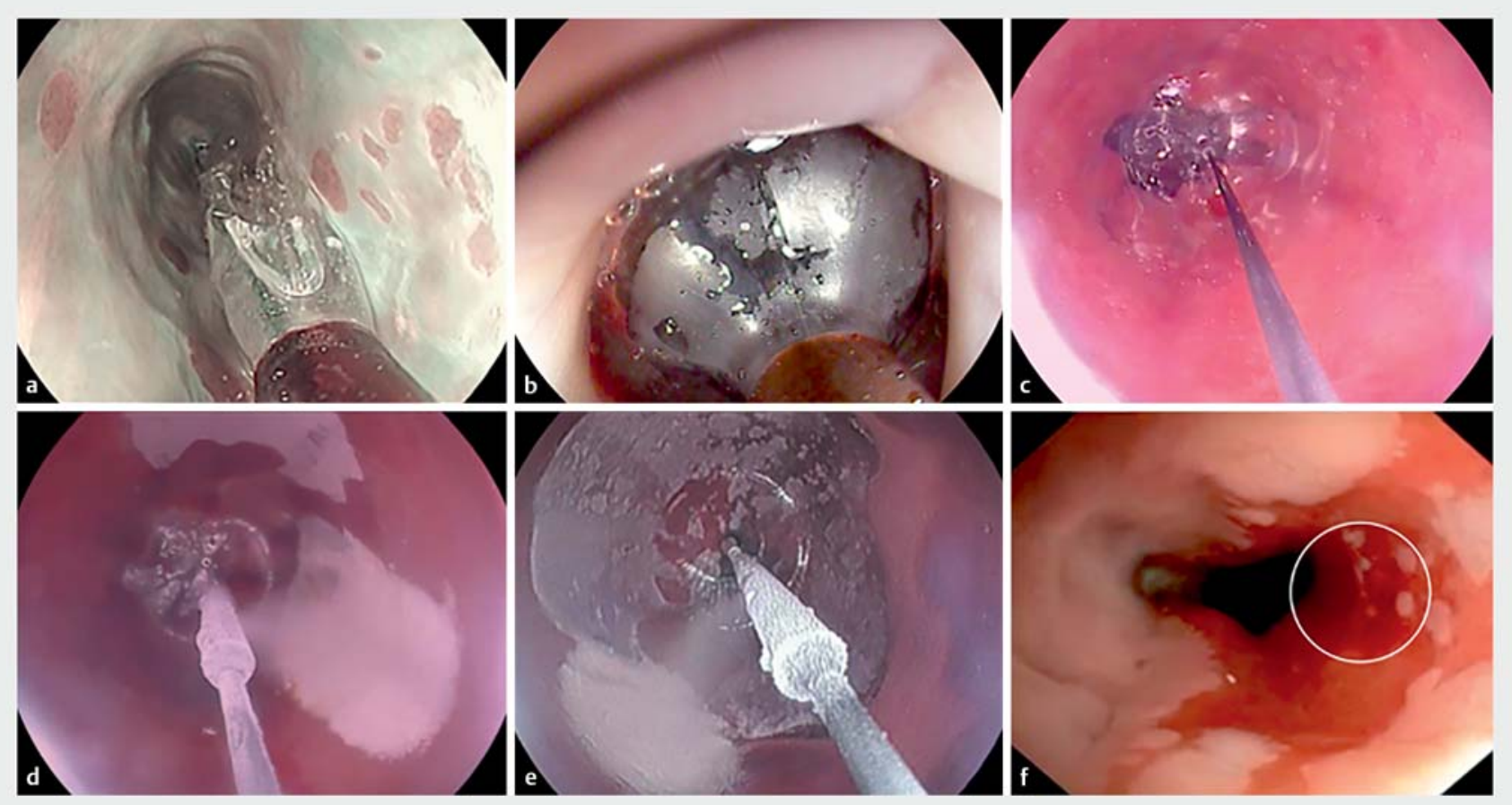

Fig. 2 a Cryoablation balloon in the oesophagus prior to insufflation. $\mathbf{b}$ Balloon partially inflated, $\mathbf{c}$ balloon fully inflated within the esophagus, and $\mathbf{d}$ cryoablation of the left and $\mathbf{e}$ right esophageal wall. $\mathbf{f}$ Post-cryoablation mucosal erythema as shown by the circled white line.

\section{Statistical analysis}

Statistical analysis was performed using the SPSS Statistics software (Version 25). Quantitative variables were expressed as median with range and qualitative variables were presented as percentages. This was a feasibility study and therefore sample size calculation was not performed. Kaplan-Meier analysis was used to determine the durability of CR-IM and CR-D post Cryoablation.

\section{Results}

A total of 18 patients with BE neoplasia (15 male, 3 female; median age 71.5, IQR 65-74), refractory to first-line EET were treated with cryoablation from June 2016 to March 2018 ( $\triangleright$ Table 1 and > Table 2, > Fig. 3 ).

Baseline sequential EET included a combination of EMR and RFA in 13 patients (72\%) and RFA only in five patients (28\%) with $B E$ neoplasia with a median length of dysplastic $B E$ treated of $3 \mathrm{~cm}$ (IQR 3-4.25) (\Table 3).

Successful ablation was achieved in 17 patients (94\%) with only one patient $(5.5 \%$ ) receiving inadequate ablation with the Cryoballoon due to a tortuous and dilated esophagus, preventing adequate contact between the mucosa and the cryoballoon device.

A median of 11 ablations (IQR 9-16) were applied per patient. Each patient received only one session of cryoablation ( $>$ Table 3). At follow-up endoscopy 3 months after treatment with cryoablation, CR-D was achieved in $78 \%$ of patients (14/ 18) and CR-IM was achieved in $39 \%$ of patients (7/18) ( $\triangleright \mathrm{Ta}$ ble 4). Lack of response to Cryoablation was seen in one patient (5.5\%) with IMC and disease progression from LGD to HGD was confirmed in one patient (5.5\%) at 3-month follow-up endoscopy ( $\triangleright$ Table 4$)$. All patients with a remaining segment of $\mathrm{BE}$ (with IM or dysplasia) post-cryoablation received further endo-

- Table 1 Baseline histology.

\begin{tabular}{|l|l|l|l|}
\hline & & $\begin{array}{l}\text { Baseline histology prior to failed } \\
\text { first-line EET }\end{array}$ & $\begin{array}{l}\text { Baseline histology prior to } \\
\text { Cryoballoon therapy }\end{array}$ \\
\hline \multirow{2}{*}{ BE neoplasia } & Low-grade dysplasia (LGD) & $4(22 \%)$ & $9(50 \%)$ \\
\hline & High-grade dysplasia (HGD) & $6(33 \%)$ & $6(33 \%)$ \\
\hline & Intramucosal carcinoma (IMC) & $8(44 \%)$ & $3(17 \%)$ \\
\hline
\end{tabular}

EET, endoscopic eradication therapy; BE, Barrett's esophagus 
- Table 2 Baseline histology with corresponding post-cryoablation histology at 3 months follow-up for all patients.

\begin{tabular}{|c|c|c|c|}
\hline $\begin{array}{l}\text { Patient } \\
\text { no. }\end{array}$ & $\begin{array}{l}\text { Pre-EET } \\
\text { histology }\end{array}$ & $\begin{array}{l}\text { Pre-cryoabla- } \\
\text { tion histology }\end{array}$ & $\begin{array}{l}\text { Post-cryoablation } \\
\text { histology }\end{array}$ \\
\hline 1 & IMC & HGD & $\begin{array}{l}\text { Normal squamous } \\
\text { mucosa }\end{array}$ \\
\hline 2 & HGD & HGD & $\begin{array}{l}\text { Normal squamous } \\
\text { mucosa }\end{array}$ \\
\hline 3 & IMC & IMC & $\begin{array}{l}\text { Normal squamous } \\
\text { mucosa }\end{array}$ \\
\hline 4 & IMC & HGD & $\begin{array}{l}\text { Normal squamous } \\
\text { mucosa }\end{array}$ \\
\hline 5 & LGD & LGD & $\begin{array}{l}\text { Normal squamous } \\
\text { mucosa }\end{array}$ \\
\hline 6 & LGD & LGD & $\begin{array}{l}\text { Normal squamous } \\
\text { mucosa }\end{array}$ \\
\hline 7 & IMC & LGD & $\begin{array}{l}\text { Normal squamous } \\
\text { mucosa }\end{array}$ \\
\hline 8 & LGD & LGD & IM only, no dysplasia \\
\hline 9 & HGD & LGD & IM only, no dysplasia \\
\hline 10 & HGD & HGD & IM only, no dysplasia \\
\hline 11 & HGD & LGD & IM only, no dysplasia \\
\hline 12 & LGD & LGD & IM only, no dysplasia \\
\hline 13 & IMC & IMC & IM only, no dysplasia \\
\hline 14 & HGD & LGD & IM only, no dysplasia \\
\hline 15 & IMC & HGD & LGD \\
\hline 16 & HGD & LGD & HGD \\
\hline $17^{1}$ & IMC & HGD & HGD \\
\hline 18 & IMC & IMC & IMC \\
\hline \multicolumn{4}{|c|}{$\begin{array}{l}\text { EET, endoscopic eradication therapy; IMC, intramucosal carcinoma; HGD, } \\
\text { high-grade dysplasia; LGD, low-grade dysplasia. } \\
1 \text { Patient received inadequate ablation with the Cryoballoon due to a tortu- } \\
\text { ous and dilated esophagus }\end{array}$} \\
\hline
\end{tabular}

scopic therapy with EMR, RFA or both, with the aim of achieving complete eradication of $\mathrm{BE}$.

There were two (11\%) reported esophageal strictures postcryoablation, each requiring one successful endoscopic dilatation. There were no recorded complications or AEs.

\section{Durability of disease reversal}

Analysis of all patients post-endoscopic therapy with cryoablation showed that CR-D was maintained in $72 \%(13 / 18)$ and CRIM in $33 \%(6 / 18)$ after a median follow-up of 19 months (IQR 13-28) (> Fig. 4).

\section{Discussion}

Endoscopic treatment of early esophageal neoplasia has significantly developed in the past decade. The current consensus is to resect any visible lesions followed by ablative therapy using
18 Patients with treatment refractory BE neoplasia enrolled into this study:

(June 2016-March 2018)

- 13 (72\%) patients had combination of EMR and RFA therapy prior to Cryoablative therapy

- 5 (28\%) patients had RFA only prior to Cryoablative therapy

\section{One session of Cryoablation (10 second ablations)} applied:

- Under conscious sedation

- By the same GI endoscopist

- At a large volume tertiary referral centre

\section{All patients received post ablative care:}

- High dose acid suppressive medication (Omeprazole 40 mg bd, Ranitidine 300 mg nocte and Sucralfate liquid $2 \mathrm{~g}$ TDS)

- Liquid diet for 24 hours followed by soft diet for 1 week

\section{All patients received follow up endoscopy at about} 3 months post cryoablation:

- All treated area were inspected with WLE, NBI/OE and chromoendoscopy with acetic acid

- Biopsies were taken from $1 \mathrm{~cm}$ below the GOJ, the $\mathrm{GOJ}$ and the remaining segment of $\mathrm{BE}$ at $2 \mathrm{~cm}$ intervals (including target biopsies from any suspicious areas)

Fig. 3 Study flowchart.

RFA or APC for BE neoplasia. Depressed lesions are associated with a high risk of submucosal invasion and would be undertreated by ablation.

RFA is safe and effective $[12,25,26]$ for treatment of BE neoplasia. ET is also more cost-effective than surgery [27]; however, the treatment can be painful and risk of stenosis post-ET is not negligible [28], especially in patients who require circumferential ablation [29].

In various studies, the rate of recurrence of $\mathrm{BE}$ and $\mathrm{BE}$ neoplasia has been documented as ranging from $5 \%$ to $40 \%$. Longterm surveillance is therefore needed to maintain remission and detect early recurrence of disease [30-33]. Non-compliance with endoscopic surveillance and failure to achieve complete remission at 12 months post-ET are predictors of progression [34]. In addition, a number of patients (2\%-25\%) [12,17] will not respond to first-line EET, therefore, alternative rescue treatment modalities other than surgery are needed as some of these patient may not be suitable surgical candidates and surgery can be associated with mortality and morbidity rates that are not negligible $[13,35,36]$. Acid suppression is an im- 
- Table 3 Baseline length of BE with corresponding number of cryoablations for each patient.

\begin{tabular}{|c|c|c|c|c|c|c|}
\hline No. & Gender & Age & Pre-EET length of $B E$ & Pre-cryoablation length of BE & Post-cryoablation length of BE & No. of cryoablation \\
\hline 1 & $\mathrm{~F}$ & 71 & C14M14 & $\mathrm{C} 1 \mathrm{M} 3$ & 4 small islands $<1 \mathrm{~cm}$ & 14 \\
\hline 2 & M & 75 & C6M7 & COM1 & All resolved & 2 \\
\hline 3 & M & 70 & $\mathrm{C} 1 \mathrm{M} 4$ & COM2 & C0M1 & 9 \\
\hline 4 & M & 83 & C10M11 & COM2 & All resolved & 11 \\
\hline 5 & M & 55 & С8M9 & СOM3 & All resolved & 12 \\
\hline 6 & $\mathrm{~F}$ & 70 & C8M8 & СОМ3 & $1 \mathrm{small}$ islands $<1 \mathrm{~cm}$ & 9 \\
\hline 7 & M & 85 & $\mathrm{C} 2 \mathrm{M} 2$ & COM3 & COM2 & 11 \\
\hline 8 & M & 63 & C7M8 & COM3 & C0M1 & 11 \\
\hline 9 & M & 63 & $\mathrm{C} 1 \mathrm{M} 10$ & $\mathrm{C} 1 \mathrm{M} 3$ & 3 small islands $<1 \mathrm{~cm}$ & 8 \\
\hline 10 & M & 63 & $\mathrm{C} 2 \mathrm{M} 3$ & COM4 & All resolved & 6 \\
\hline 11 & $\mathrm{~F}$ & 73 & C4M7 & СОМ3 & All resolved & 4 \\
\hline 12 & M & 76 & C14M14 & сOM10 & COM2 & 22 \\
\hline 13 & M & 65 & C9M15 & СОМ3 & All resolved & 9 \\
\hline 14 & M & 70 & C16M16 & C6M8 & C4M6 & 24 \\
\hline 15 & M & 74 & $\mathrm{C} 2 \mathrm{M} 4$ & C1M3 & All resolved & 10 \\
\hline 16 & M & 74 & C10M11 & C6M6 & $\mathrm{C} 1 \mathrm{M} 2$ & 18 \\
\hline 17 & M & 74 & C7M8 & $\mathrm{C} 2 \mathrm{M} 4$ & $\mathrm{C} 1 \mathrm{M} 2$ & 15 \\
\hline 18 & M & 72 & $\mathrm{C} 8 \mathrm{M} 8$ & C1M5 & COM4 & 19 \\
\hline
\end{tabular}

- Table4 Summary of results.

Technical difficulty due to Anatomy

$5.5 \%(1 / 18)$ Tortuous and dilated esophagus

Stenosis

No response

Progression

CR-D

CR-IM

$11 \%(2 / 18)$

$5.5 \%(1 / 18) 1$ case with IMC

$5.5 \%(1 / 18)$ Progressed from LGD to $\mathrm{HGD}$

$78 \%(14 / 18)$

$39 \%(7 / 18)$

IMC, intramucosal carcinoma; LGD, low-grade dysplasia; HGD, high-grade dysplasia; CR-D, complete remission of dysplasia; CR-IM, complete remission of intestinal metaplasia

portant factor in treatment of patients with BE and refractory disease. GORD is associated with $\mathrm{BE}$, therefore, controlling acid reflux is an essential part of treatment. Uncontrolled acid reflux is associated with persistent IM post-RFA. Persistent acid reflux is also associated with a higher mean number of RFA sessions needed to achieve CR-IM and recurrence of disease after EET $[37,38]$. Challenging anatomy due to dilated and tortuous esophagus and strictures post-EET and presence of submucosal carcinoma has been shown to limit efficacy of endoscopic therapy and subsequently result in treatment failure and relapse [12].

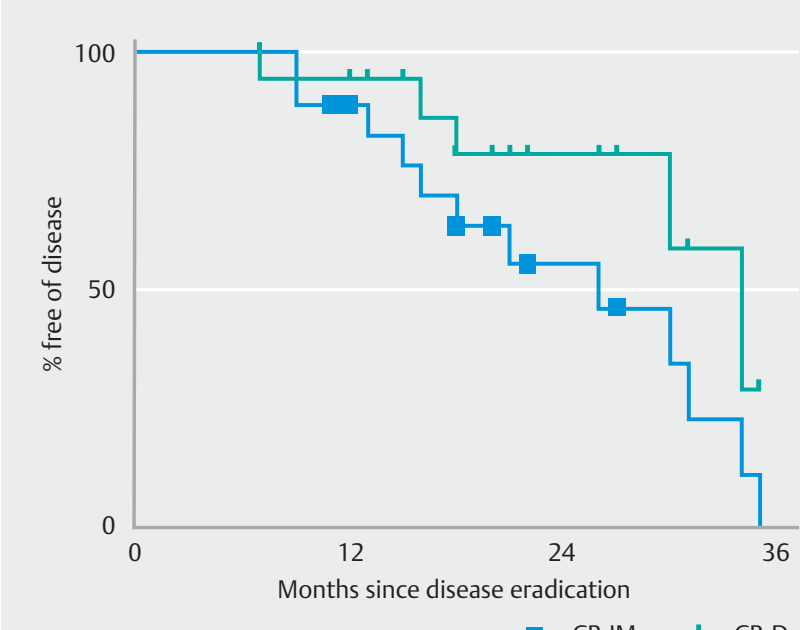

$\rightarrow$ CR-IM CR-D

-Fig. 4 Kaplan-Meier curve showing the durability of disease reversal in all patients with BE neoplasia, treated with Cryoballoon therapy.

Cryoballoon therapy using nitrous oxide as the cryogenic agent is a novel new therapy for management of early BE neoplasia which has been shown to be safe and effective with success rates comparable to that of RFA [22, 39]. In this single-center, prospective, feasibility cohort study, cryoablation with the Cryoballoon device appeared to be a viable treatment modality 
in patients with BE neoplasia refractory to sequential first-line EET.

In this study, CR-D and CR-IM could be achieved in patients who previously did not respond completely to standard first-line EET. We were able to achieve these eradication rates (CR-D: $78 \%$ and CR-IM: $39 \%$ in patient with BE) with only one session of cryoablation in treatment-refractory patients with a wide range of pre-cryoablation pathologies including LGD, HGD and IMC.

We were also able to demonstrate durability of disease reversal with $72 \%$ of patients (13/18) with BE neoplasia maintaining CR-D and $33 \%$ of patients (6/18) maintaining CR-IM after a median follow-up of 19 months (IQR 13-28).

Our data are in line with previously published series (CR-D achieved in $75 \%-88 \%$ of patients) [17, 23,40]. A recent meta-analysis by Visrodia et al analyzed 11 studies with 148 patients with BE treated with cryotherapy for persistent dysplasia or IM after RFA. CR-D was achieved in 76.0\% $(95 \% \mathrm{Cl}, 57.7-88.0)$ and CR-IM in $45.9 \%$ (95\% Cl, 32.0-60.5) of patients [41].

We have also shown that cryoablation is safe with an acceptable stricture rate. The documented symptomatic stricture rate from several major studies on BE endotherapy range from $2.1 \%$ to $14 \%[13,29,42]$ requiring a median of two to four dilatations post-endotherapy. Despite circumferential ablation of the GOJ in all patients and a pre-ablation EMR rate of $71 \%$, we were able to show a stricture rate of $11 \%$, which is comparable to that reported in similar studies $[39,43,44]$.

The benefit of cryoablative therapy over RFA is due to intrinsic and technical differences between the two modalities. The rapid freeze and thaw cycles delivered by cryotherapy achieves a greater depth of tissue penetration with relative preservation of tissue architecture [45]. Cryotherapy is minimally destructive to the structural components of tissue, such as collagen, whereas heat-based ablation techniques like RFA, irreversibly destroy proteins and therefore affect the architecture of the collagen matrix [20]. The effects of cryoablation are dose-dependent. Overlap of ice patches on adjacent treated sites may result in higher application of cryogen and deeper injury and subsequent stricture development [43]. The Cryoballoon pressure is regulated by the controller to $3.5 \mathrm{lb}$-force per square inch (psi), which is significantly lower than dilating balloons, which exert pressures of 44 to 147 psi [46]. Procedure times for cryoballoon ablation are short and the portability and ease of use of the Cryoballoon ablation device is appealing.

Our data suggest that Cryoballoon ablation is a promising treatment for refractory BE neoplasia. Our study showed that this technique is relatively easy and quick without serious AEs. It allows treatment of large circumferential areas in the esophagus as well as small islands. There are no significant published data showing how deep cryoablation can reach into the mucosa or submucosa. Several studies in BE neoplasia [23] and other fields of medicine have shown that cryoablation is less painful $[47,48]$. Pain perception was not formally assessed in this study, but previous studies have shown that the cooling process may have an anaesthetic effect [49] by reducing or blocking nerve conduction and, therefore, less postprocedural discomfort than that seen with RFA [47]. In addition, vasoconstric- tion of blood vessels as a result of the cooling process may reduce development of edema and release of painful inflammatory mediators [50].

There were some limitations to this study. First, there was a small sample size and patients were treated in a single high-volume tertiary referral center with no control group, which was due to only a small number of treatment-refractory patients with residual disease in our hospital. An increase in the number of patients may alter the results achieved. In addition, it may have been possible for patients with long segments of BE refractory to RFA sessions to achieve CR-IM if further RFA therapy sessions were utilized, therefore, cryoablation may have never been required. The median segment of treated $B E$ was $3 \mathrm{~cm}$ and the efficacy of cryoablation on long segments of BE refractory to EET is yet to be studied.

There was no formal assessment of pain perception and use of analgesia among patients participating in this study.

There was only a relatively short follow-up period after treatment, which is important taking into account the late recurrence of disease reported in major studies. This has, therefore, limited the conclusions regarding the risk of progression or recurrence in this high-risk group of patients.

Side-by-side ablation for 10 seconds of a large segment of BE may be time-consuming. Our study did not formally assess the duration of the procedures.

Finally, analysis for determinants for successful ablation and for complications was not performed.

\section{Conclusion}

In conclusion, cryoablation is a promising treatment for patients with BE neoplasia refractory to first-line EET. The CR-D and CR-IM rates achieved in this study and the encouraging safety profile show that it may be an alternative therapeutic modality for those that are not suitable for RFA or in cases where RFA was not successful.

Longer-term follow-up is needed to determine complete remission durability for cryoablation with application to larger/ circumferential areas to determine efficacy and stricture rate. Further studies to illicit the effects of two or more sessions of cryoablation with randomized controlled trials and comparison with RFA are recommended.

\section{Competing interests}

The authors declare that they have no conflict of interest.

\section{References}

[1] Spechler SJ. Barrett's esophagus and esophageal adenocarcinoma: pathogenesis, diagnosis, and therapy. Med Clin North Am 2002; 86 : 1423-1445

[2] Poehlmann A, Kuester D, Malfertheiner P et al. Inflammation and Barrett's carcinogenesis. Pathol Res Pract 2012; 208: 269-280 
[3] Pohl H, Welch $\mathrm{H}$. The role of overdiagnosis and reclassification in the marked increase of esophageal adenocarcinoma incidence. J Natl Cancer Inst 2005; 97: 142-146

[4] Hur C, Miller M, Kong CY et al. Trends in esophageal adenocarcinoma incidence and mortality. Cancer 2013; 119: 1149-1158

[5] Hvid-Jensen F, Pedersen L, Drewes AM et al. Incidence of adenocarcinoma among patients with Barrett's esophagus. N Engl J Med 2009; 365: 2301-2303

[6] Fernando HC, Murthy SC, Hofstetter W et al. The Society of Thoracic Surgeons Practice Guideline Series: Guidelines for the Management of Barrett's Esophagus With High-Grade Dysplasia. AnnThorac Surg 2009; 87: 1993-2002

[7] Prasad G, Wang K, Buttar $\mathrm{N}$ et al. Long-term survival following endoscopic and surgical treatment of high-grade dysplasia in Barrett's esophagus. Gastroenterology 2007; 132: 1226-1233

[8] Stein HJ, Hutter J, Feith $M$ et al. Limited surgical resection and jejunal interposition for early adenocarcinoma of the distal esophagus. Semin Thorac Cardiovasc Surg 2007; 19: 72-78

[9] Shimada H, Nabeya Y, Matsubara $\mathrm{H}$ et al. Prediction of lymph node status in patients with superficial esophageal carcinoma: Analysis of 160 surgically resected cancers. Am J Surg 2006; 191: 250-254

[10] Lipman G, Haidry R. Endoscopic management of Barrett's and early oesophageal neoplasia. Frontline Gastroenterol 2017; 8: 138-142

[11] Ganz RA, Utley DS, Stern RA et al. Complete ablation of esophageal epithelium with a balloon-based bipolar electrode: A phased evaluation in the porcine and in the human esophagus. Gastrointest Endosc 2004; 60: 1002-1010

[12] Phoa K, Pouw R, Bisschops R et al. Multimodality endoscopic eradication for neoplastic Barrett oesophagus: Results of an European multicentre study (EURO-II). Gut 2016; 65: 555-662

[13] Desai M, Saligram S, Gupta N et al. Efficacy and safety outcomes of multimodal endoscopic eradication therapy in Barrett's esophagusrelated neoplasia: a systematic review and pooled analysis. Gastrointest Endosc 2017; 85: 482-495

[14] Haidry RJ, Lipman G, Banks M et al. Comparing outcome of radiofrequency ablation in Barrett's with high grade dysplasia and intramucosal carcinoma: A prospective multicenter UK registry. Endoscopy 2015; 47: 980-987

[15] Pasricha S, Bulsiewicz W, Hathorn K et al. Durability and predictors of successful radiofrequency ablation for Barrett's esophagus. Clin Gastroenterol Hepatol 2014; 12: 1840-1847

[16] Krishnamoorthi R, Singh S, Ragunathan K et al. Risk of recurrence of Barrett's esophagus after successful endoscopic therapy. Gastrointest Endosc 2016; 83: 1090-1106

[17] Sengupta N, Ketwaroo GA, Bak DM et al. Salvage cryotherapy after failed radiofrequency ablation for Barrett's esophagus - related dysplasia is safe and effective. Gastrointest Endosc 2015; 82: 443-448

[18] Gage A, Baust J. Mechanisms of tissue injury in cryosurgery. Cryobiology 1998; 37: 171-186

[19] Baust J, Gage A, Klossner D et al. Issues critical to the successful application of cryosurgical ablation of the prostate. Technol Cancer Res Treat 2007; 6: 97-109

[20] Evonich R, Nori D, Haines D. A randomized trial comparing effects of radiofrequency and cryoablation on the structural integrity of esophageal tissue. J Interv Card Electrophysiol 2007; 19: 77-83

[21] Künzli H, Schölvinck D, Meijer S et al. Efficacy of the Cryoballoon focal ablation system for the eradication of dysplastic Barrett's esophagus islands. Endoscopy 2016; 49: 169-175

[22] Schölvinck DW, Künzli HT, Kestens C et al. Treatment of Barrett' s esophagus with a novel focal cryoablation device: a safety and feasibility study. Endoscopy 2015: 1106-1112

[23] Van Munster S, Overwater A, Haidry R et al. Focal cryoballoon versus radiofrequency ablation of dysplastic Barrett's esophagus: impact on treatment response and postprocedural pain. Gastrointest Endosc 2018; 88: 1-9

[24] Friedland S, Triadafilopoulos G. A novel device for ablation of abnormal esophageal mucosa (with video). Gastrointest Endosc 2011; 74: 182-188

[25] Magee C, Gordon C, Dunn J et al. Outcomes of 360 HALO express radio-frequency ablation for Barrett's Oesophagus related neoplasia. Abstract presented at BSG annual conference 2018

[26] Haidry RJ, Butt MA, Dunn JM et al. Improvement over time in outcomes for patients undergoing endoscopic therapy for Barrett's oesophagus-related neoplasia: 6-year experience from the first 500 patients treated in the UK patient registry. Gut 2015; 64: 1192-1199

[27] Inadomi ], Somsouk M, Madanick D et al. A cost-utility analysis of ablative therapy for Barrett's esophagus. Gastroenterology 2009; 136: 2101-2114

[28] Haidry R, Lovat L. Long-term durability of radiofrequency ablation for Barrett's-related neoplasia. Curr Opin Gastroenterol 2015; 31: 316320

[29] Magee C, Gordon C, Dunn J et al. Halo 360 express radio-frequency ablation in the treatment of barrett's oesophagus - The first $100 \mathrm{va}$ ses treated in the United Kingdom. BSG annual conference; 2017

[30] Orman E, Nan L, Shaheen N. Efficacy and durability of radiofrequency ablation for barrett's esophagus: systematic review and meta-analysis. Clin Gastroenterol Hepatol 2013; 11: 1-20

[31] Gupta M, lyer P, Lutzke L et al. Recurrence of Esophageal intestinal metaplasia after endoscopic mucosal resection and radiofrequency ablation of Barrett's esophagus: Results from a US multicenter consortium recurrence of Barrett's esophagus after EMR and RFA. Gastroenterology 2013; 145: 79-86

[32] Pech O, Behrens A, May A et al. Long-term results and risk factor analysis for recurrence after curative endoscopic therapy in 349 patients with high-grade intraepithelial neoplasia and mucosal adenocarcinoma in Barrett's oesophagus. Gut 2008; 57: 1200-1206

[33] Cotton C, Wolf W, Pasricha S et al. Recurrent intestinal metaplasia after radiofrequency ablation for Barrett's esophagus: endoscopic findings and anatomic location. Gastrointest Endosc 2015; 81: 13621369

[34] Fasanella K, McGrath K. The Ice Age reborn? Gastrointest Endosc 2019; 90: 213-214

[35] Kerry B, Dunbar S. The risk of lymph node metastases in patients with high grade dysplasia or intramucosal carcinoma in Barrett's Esophagus: a systematic review. Am J Gastroenterol 2012; 107: 850-862

[36] Yong E, Han X, Watson D et al. Outcome following surgery for squamous cell carcinoma of the oesophagus. ANZ J Surg 2009; 79: $724-$ 728

[37] Krishnan K, Pandolfino J, Kahrilas P et al. Increased risk for persistent intestinal metaplasia in patients with Barrett's esophagus and uncontrolled reflux exposure before radiofrequency ablation. Gastroenterology 2012; 143: 576-581

[38] Komanduri S, Kahrilas P, Krishnan K et al. Recurrence of Barrett's esophagus is rare following endoscopic eradication therapy coupled with effective reflux control. Am J Gastroenterol 2017; 112: 556-566

[39] Gosain S, Mercer K, Twaddell W et al. Liquid nitrogen spray cryotherapy in Barrett's esophagus with high-grade dysplasia: Long-term results. Gastrointest Endosc 2013; 78: 260-265

[40] Dumot J, Vargo J, Falk G et al. An open-label, prospective trial of cryospray ablation for Barrett's esophagus high-grade dysplasia and early esophageal cancer in high-risk patients. Gastrointest Endosc 2009; 70: 635-644

[41] Visrodia K, Zakko L, Singh S et al. Cryotherapy for persistent Barrett's esophagus after radiofrequency ablation: a systematic review and meta-analysis. Gastrointest Endosc 2018; 87: 1396-1404 
[42] Yang D, Zou F, Xiong S et al. Endoscopic submucosal dissection for early Barrett's neoplasia: a meta-analysis. Gastrointest Endosc 2018; 87: $1383-1393$

[43] Canto M, Shaheen N, Almario J et al. Multifocal nitrous oxide cryobalIoon ablation with or without EMR for treatment of neoplastic Barrett's esophagus. Gastrointest Endosc 2018; 88: 438-446

[44] Greenwald B, Dumot J, Abrams J et al. Endoscopic spray cryotherapy for esophageal cancer: safety and efficacy. Gastrointest Endosc 2010; 71: 686-693

[45] Van Munster S, Overwater A, Raicu M et al. A novel cryoballoon ablation system for eradication of dysplastic Barrett's esophagus: a firstin-human feasibility study. Endoscopy 2020; 52: 193-201

[46] Canto M. Cryotherapy for Barrett's esophagus. Gastrointest Endosc Clin N Am 2017; 27: 503-513
[47] Truesdale C, Soulen M, Clark T et al. Percutaneous computed tomography-guided renal mass radiofrequency ablation versus cryoablation: Doses of sedation medication used. J Vasc Interv Radiol 2013; 24: $347-350$

[48] Bastani H, Drca N, Insulander P et al. Cryothermal vs. radiofrequency ablation as atrial flutter therapy: A randomized comparison. Europace 2013; 15: 420-423

[49] Erinjeri J, Clark T. Cryoablation: Mechanism of action and devices. J Vasc Interv Radiol 2010; 21: S187-S191

[50] Allaf M, Varkarakis I, Bhayani S et al. Pain control requirements for percutaneous ablation of renal tumors: cryoablation versus radiofrequency ablation - initial observations. Radiology 2005; 237: 366-370 